\title{
Os processos mentais nas representações de homens e mulheres heterossexuais
} em anúncios pessoais eletrônicos

\author{
Mental processes in heterosexual male and female representations in \\ online personal ads \\ Vitor Hugo Chaves Costa \\ Instituto Federal de Educação, Ciência e Tecnologia Farroupilha, Alegrete, RS
}

Resumo: O presente artigo investiga como homens e mulheres heterossexuais representam a si mesmos (as) e seus (suas) parceiros (as) projetados (as) em anúncios pessoais eletrônicos. Com base na Linguística Sistêmico-Funcional, foram explorados os processos mentais empregados nessas situações de interação. O corpus consiste de 500 anúncios publicados no Viva Anúncios, um site gratuito destinado a anúncios pessoais. A ferramenta Wordsmith foi aplicada para identificar os processos mentais mais frequentes e seus Fenômenos e orações projetadas. Os resultados revelam que o Fenômeno ou a oração projetada de um mesmo processo mental pode variar nos anúncios masculinos e femininos, evocando ideologias e representações sociais de sexualidade e gênero.

Palavras-chave: Anúncios pessoais eletrônicos, processos mentais, Fenômeno, gênero

Abstract: The present article investigates how heterosexual women and men represent themselves and their potential mates in online personal ads. Drawing on Systemic Functional Linguistics, it explores the mental processes used in these interactive situations. The data consists of 500 ads from Viva Anúncios, a Brazilian free online advertising site. The Wordsmith tool was applied in order to identify the 
most frequent mental processes and their Phenomena and projected clauses. The analysis reveals that the Phenomenon or projected clause of the same mental process may vary in male and female ads, evoking ideologies and social representations of sexuality and gender.

Keywords: Online personal ads, mental processes, Phenomenon, gender

\section{Introdução}

A Linguística Sistêmico-Funcional (LSF) postula que a língua é um po-

Vitor Hugo Chaves Costa tencial de significados ao qual recorremos para construir significado em nossas interações sociodiscursivas (EGGINS, 1994; HALLIDAY; MATTHIESSEN, 2004; BARBARA; MACEDO, 2009; THOMPSON, 2014). 0 aspecto semântico da língua, nessa perspectiva linguística, é o elemento principal, sendo o significado concebido como o determinador da forma. De acordo com a LSF, podemos construir simultaneamente três formas de significados (ideacional, interpessoal e textual), realizados por intermédio da léxico-gramática, os quais correspondem, respectivamente, às metafunções ideacional, interpessoal e textual (HALLIDAY, 1994; MARTIN; ROSE, 2008; VIAN JR, 2009). A metafunção ideacional refere-se à maneira como usamos a língua para expressar nossas experiências dos mundos material e interno (consciência). Essa é dividida em duas subfunções (experiencial e lógica). $\mathrm{Na}$ análise oracional, é observada a transitividade, construída de três papéis básicos: os processos, os participantes e as circunstâncias (HALLIDAY; MATTHIESSEN, 2004). Os principais processos são: materiais, mentais, relacionais, verbais, comportamentais e existenciais. No presente estudo, buscamos investigar como os (as) anunciantes representam a si mesmos (as) e seus/suas parceiros (as) projetados (as) em anúncios pessoais eletrônicos, a partir da investigação do emprego dos processos mentais nessa interação sociodiscursiva.

\section{O Sistema de Transitividade}

A metafunção ideacional, na qual a oração é vista como representação, tem relação com o modo como empregamos a língua para expressar nossas experiências dos mundos material e interno. As experiências externas (do mundo material) correspondem às ações e aos eventos desencadeados por atores; já as experiências internas (da consciência) são constituídas pelas lembranças, pelas reações, pelas reflexões e pelos estados de espírito (FUZER; CABRAL, 2014; HALLIDAY; MATTHIESSEN, 2004). 
A transitividade é um recurso léxico-gramatical que serve para representar ações e atividades. Ela é construída, gramaticalmente, com base em três elementos: os processos (grupos verbais), os participantes (grupos nominais) e as circunstâncias (grupos adverbais). De outra forma, a transitividade é um recurso linguístico que explicita quem fez o quê a quem em que circunstâncias (GOUVEIA, 2009, p.30).

Os seis processos apresentados por Halliday (1994) estão apresentados no Quadro 1 de forma resumida, além de seus significados, seus participantes e alguns exemplos de cada um deles.

\begin{tabular}{|c|c|c|c|}
\hline PROCESSOS & SIGNIFICADOS & PARTICIPANTES & EXEMPLOS \\
\hline $\begin{array}{l}\text { Comporta- } \\
\text { mentais }\end{array}$ & Comportar-se & Comportante & $\begin{array}{l}\text { Para as pessoas } \\
\text { brigarem ou olharem } \\
\text { defeitos [C1\#217] }\end{array}$ \\
\hline Materiais & $\begin{array}{l}\text { Fazer } \\
\text { Acontecer }\end{array}$ & $\begin{array}{l}\text { Ator } \\
\text { Meta } \\
\text { Escopo } \\
\text { Beneficiário } \\
\text { Atributo }\end{array}$ & $\begin{array}{l}\text { Posso traduzir, ensi- } \\
\text { nar, fazer recepção } \\
\text { em eventos, hostels } \\
\text { ou guesthouses e } \\
\text { cozinhar [C2\#209]. }\end{array}$ \\
\hline Mentais & $\begin{array}{l}\text { Perceber } \\
\text { Pensar } \\
\text { Sentir } \\
\text { Desejar }\end{array}$ & $\begin{array}{l}\text { Experienciador } \\
\text { Fenômeno }\end{array}$ & $\begin{array}{l}\text { Adoro o sol, o mar } \\
\text { e a beleza da vida } \\
\text { [C1\#87]. }\end{array}$ \\
\hline Relacionais & $\begin{array}{l}\text { Caracterizar } \\
\text { Identificar }\end{array}$ & $\begin{array}{l}\text { Portador } \\
\text { Atributo } \\
\text { Identificado } \\
\text { Identificador }\end{array}$ & $\begin{array}{l}\text { Sou um cara trabalha- } \\
\text { dor, não uso drogas } \\
\text { nem fumo, bebo } \\
\text { socialmente [C2\#11]. }\end{array}$ \\
\hline Verbais & Dizer & $\begin{array}{l}\text { Dizente } \\
\text { Verbiagem } \\
\text { Receptor } \\
\text { Alvo }\end{array}$ & $\begin{array}{l}\text { Com toda minha } \\
\text { sinceridade, digo } \\
\text { que: infelizmente não } \\
\text { posso oferecer jóias } \\
\text { e muito menos bens } \\
\text { materiais [C2\#117] }\end{array}$ \\
\hline Existenciais & Existir & Existente & $\begin{array}{l}\text { Existe homem feio } \\
\text { e de todo tipo, eu } \\
\text { não dou importância } \\
\text { [C1\#77] }\end{array}$ \\
\hline
\end{tabular}

\section{Quadro 1: A transitividade}

Elaborada com base em FUZER, TICKS; CABRAL (2012)

Em nosso estudo, centramo-nos, em especial, nos processos mentais, os quais são empregados pelos anunciantes para expressar seus desejos, emoções, cognições e percepções em anúncios pessoais eletrônicos. 


\section{Os processos mentais}

Os processos mentais servem para representar as experiências do mundo interior (a consciência), indicando a cognição, o afeto, a percepção e o desejo. Os participantes das orações mentais são tipicamente humanos ou coletivos humanos, os quais sentem, pensam, percebem e desejam. Por essa razão, é denominada Experienciador a função léxico-gramatical que desempenham na oração (FUZER; CABRAL, 2014). Já o que é pensado, desejado, percebido e sentido é denominado Fenômeno, realizado gramaticalmente por grupos nominais, grupos verbais ou ora-

Vitor Hugo Chaves Costa ções inteiras. Os Fenômenos podem ser elementos como fatos, pessoas, objetos, animais, abstrações, dentre outros. Como exemplos de ocorrências de processos mentais, temos as seguintes orações, extraídas de nosso corpus de pesquisa:

Gosto de sair com a namorada sozinho [C2\#48]. ${ }^{1}$

\begin{tabular}{|c|c|c|}
\hline$(\mathrm{Eu})$ & Gosto & de sair com a namorada sozinho. \\
\hline Experienciador & Processo Mental & Fenômeno \\
\hline
\end{tabular}

Amo estar em contato com a natureza [C1\#148].

\begin{tabular}{|c|c|c|}
\hline$(\mathrm{Eu})$ & Amo & estar em contato com a natureza. \\
\hline Experienciador & Processo Mental & Fenômeno \\
\hline
\end{tabular}

Detesto funk e seus derivados [C1\#142]

\begin{tabular}{|c|c|c|}
\hline$(\mathrm{Eu})$ & Detesto & funk e seus derivados \\
\hline Experienciador & Processo Mental & Fenômeno \\
\hline
\end{tabular}

Halliday e Matthiessen (2004) subdividem os processos mentais em quatro categorias: perceptivos, cognitivos, desiderativos e emotivos. Os perceptivos estão relacionados aos sentidos (audição, olfato, visão, etc.); os cognitivos remetem à cognição humana; os desiderativos estão ligados aos desejos, às vontades e aos interesses; os emotivos servem para expressar as emoções.

No Quadro 2, baseado em Halliday e Matthiessen (2004, p. 210) e Fuzer e Cabral (2014, p. 58), apresentamos alguns exemplos de processos mentais. Notemos que nem sempre o processo mental é comple-

1. Os exemplos do corpus não foram revisados em termos de forma, pois não queríamos alterá-los. Qualquer alteração tiraria a originalidade dos textos e comprometeria a análise dos processos mentais. 
mentado por um Fenômeno propriamente dito. Muitas vezes, a complementação acontece através de uma oração projetada do tipo citação ou relato, como é o caso dos processos cognitivos e desiderativos.

Os processos

mentais nas

\begin{tabular}{|c|c|c|}
\hline $\begin{array}{c}\text { PROCESSOS } \\
\text { MENTAIS }\end{array}$ & VERBOS & EXEMPLOS \\
\hline Perceptivos & $\begin{array}{c}\text { Cheirar, escutar, ouvir, olhar, } \\
\text { perceber, saborear, notar, } \\
\text { pressentir, experimentar. }\end{array}$ & $\begin{array}{c}\text { Vejo a felicidade nas coisas } \\
\text { pequenas e mais simples da } \\
\text { vida [C2\#4]. }\end{array}$ \\
\hline Cognitivos & $\begin{array}{c}\text { Achar, acreditar, aguardar, } \\
\text { lembrar, perceber, refletir, } \\
\text { saber, convencer, considerar. }\end{array}$ & $\begin{array}{c}\text { Sei que este homem está em } \\
\text { algum lugar [C1\#141]. }\end{array}$ \\
\hline Desiderativos & $\begin{array}{c}\text { Almejar, desejar, esperar, } \\
\text { estabelecer, querer, recu- } \\
\text { sar, rejeitar, tencionar. }\end{array}$ & $\begin{array}{c}\text { Desejo conhecer uma mu- } \\
\text { lher para relacionamento } \\
\text { sério que more em Jundiaí } \\
\text { ou em São Paulo [C2\#244]. }\end{array}$ \\
\hline Emotivos & $\begin{array}{c}\text { Adorar, amar, apreciar, de- } \\
\text { testar, gostar, odiar, sofrer. }\end{array}$ & $\begin{array}{c}\text { Sou muito companheira e } \\
\text { detesto traição [C1\#179]. }\end{array}$ \\
\hline
\end{tabular}

representações

de homens

e mulheres

heterossexuais

em anúncios

pessoais

eletrônicos

\section{Quadro 2: Tipos de processos mentais}

Como já mencionamos, investigamos o emprego dos processos mentais em anúncios pessoais eletrônicos. Para tanto, adotamos uma perspectiva de gêneros discursivos que considera a linguagem como elemento intrinsicamente relacionado ao social.

\section{Anúncio pessoal eletrônico como gênero discursivo}

Na visão de Bakhtin (2003), os gêneros discursivos são tipos de enunciados relativamente estáveis, que são utilizados em situações reais de comunicação, com base em propósitos comunicativos. Seguindo uma perspectiva social, porém numa abordagem sócio-semiótica, a LSF compreende os gêneros discursivos a partir da noção de contexto cultural (HALLIDAY; HASAN, 1989; EGGINS, 1994; MARTIN; WHITE, 2005). Desse modo, a concepção de contexto torna-se crucial para compreendermos esses elementos.

A LSF considera a análise de dois tipos de contextos: o contexto de situação (registro) e o contexto de cultura. 0 primeiro apresenta três variáveis (o campo, as relações e o modo), as quais influenciam a forma e os significados dos textos. Ikeda e Vian Jr (2006, p.19), com base em Halliday (1994), afirmam que o campo diz respeito à natureza da atividade social e ao assunto; as relações referem-se aos papéis assumidos pelos interlocutores e os relacionamentos entre eles; já o modo concer- 
Vitor Hugo Chaves Costa

ne às formas de uso (oral e escrita) e ao canal ou meio de comunicação. Relacionadas ao campo, às relações e ao modo, existem as metafunções: ideacional (campo), interpessoal (relações) e textual (modo). Essas são realizadas por intermédio da léxico-gramática (HALLIDAY, 1994).

Por outro lado, o contexto de cultura abrange as convenções sociais, as ideologias, as representações sociais e os aspectos culturais. Na análise desse contexto, a noção de "gêneros discursivos", que são utilizados pelos falantes para atingir propósitos comunicativos e sociais, é primordial, porque neles são manifestados e (re) construídos os elementos mencionados anteriormente.

$O$ acesso de um falante ao gênero discursivo é mediado pelos diversos discursos das classes sociais, pelas sexualidades, pelas etnias e gerações, dentre outros (MARTIN, 1992; VIAN JR.; LIMA-LOPES, 2005). Nos anúncios pessoais eletrônicos, os quais investigamos neste estudo, notamos a existência, especialmente, dos discursos das sexualidades, que (re)constroem as relações dos gêneros masculino e feminino.

Os gêneros discursivos são considerados como configurações recorrentes de significados, que tornam possíveis as práticas sociais de uma determinada cultura. Eles estão situados no extrato da cultura, numa dimensão acima do registro. Tais gêneros, assim, funcionam como modeladores para os padrões de campo, relações e modo. Em nosso entendimento, para cada tipo de gênero, há uma configuração particular dessas variáveis (MARTIN; ROSE, 2008). A Figura 1 ilustra a relação existente entre o gênero discursivo, o registro e a língua.

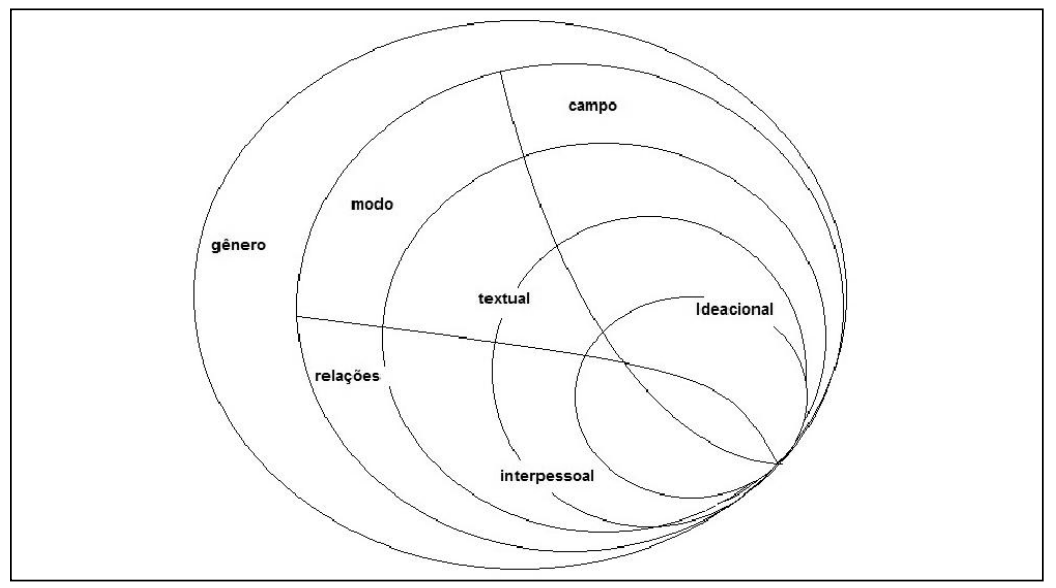

Figura 1: Gênero discursivo em relação ao registro e à língua (MARTIN; ROSE, 2008). Adaptação de Soares (2013) 
No caso dos anúncios pessoais eletrônicos, que são usados em situações nas quais sujeitos buscam estabelecer uma relação de amizade, amor e/ou sexo com um (uma) parceiro (a) projetado (a), temos a seguinte configuração (Quadro 3):

Os processos mentais nas representações de homens e mulheres heterossexuais

Relacionamentos amorosos, sexuais e de amizade na esfera heterossexual discursiva.
Anunciantes e parceiros projetados heterossexuais.

Distância social máxima entre os interactantes (não se conhecem pessoalmente e podem estar em locais muito distantes).
Linguagem escrita no meio eletrônico.

em anúncios

pessoais

eletrônicos

Quadro 3: Variáveis do contexto de situação nos anúncios pessoais eletrônicos

O anúncio pessoal é uma prática discursiva de autopromoção, isto é, o anunciante produz um texto que constitui uma visão de si para ser consumida por uma determinada clientela (COUPLAND, 1996; PRADO; MOTTA-ROTH, 2006). Para tanto, um dos recursos linguísticos empregados são os processos mentais. Esses, conforme já informamos, servem para expressar os desejos, as emoções, as cognições e os sentidos de uma pessoa.

No que concerne aos aspectos socioculturais envolvidos no uso dos anúncios pessoais Eeletrônicos, os que se referem às relações de gêneros sociais (masculino e feminino) exercem função primordial.

\section{Os gêneros e os relacionamentos}

Nas práticas discursivas, como o anúncio pessoal eletrônico, construímos nossas identidades como masculinos, femininos, homoeróticos, heterossexuais e bissexuais. Essas identidades têm, como pano de fundo, as ideologias e as representações sociais dos gêneros masculino e feminino e das sexualidades (LOURO, 2004; MOITA-LOPES, 2003; PIRES; FERRAZ, 2008).

Em nosso contexto cultural, existe um paradigma naturalista, o qual molda as relações entre homens e mulheres, baseando-se numa pseudonatureza superior dos homens e numa visão heterossexualizada do mundo (WELZER-LANG, 2001). Tal paradigma é reproduzido e refor- 
çado nos discursos de algumas instituições (escolas, famílias e igrejas), de certas áreas de atuação profissionais e da mídia (BOURDIEU, 2005). No que se refere à mídia, predomina o discurso heteronormativo das diferenças de gênero. Esse discurso reforça um tipo estereotipado de masculinidade e de feminilidade por meio de imagens de mulheres sensuais e magras, bem como de homens atleticamente másculos (MOITA-LOPES, 2009; JESUS, 2014).

Butler (1993) e Louro (2004) afirmam que há algumas representações sociais de como os sujeitos devem comportar-se sexualmente em

Vitor Hugo Chaves Costa nossa cultura. No que concerne ao grupo social masculino, temos uma representação social de masculinidade hegemônica e dominante, a qual determina que os homens devem ser dominadores, ativos nas relações sexuais, racionais e viris, dentre outros atributos (MOITA-LOPES, 2003; SILVA, 2006). O grupo social feminino, por sua vez, é influenciado por uma representação social de feminilidade que estabelece alguns atributos às mulheres, tais como serem passivas em relações sexuais, voltadas às atividades domésticas e à maternidade, além de serem emocionais. Esclarecemos que não estamos de acordo com tais representações, porque elas representam uma visão preconceituosa e sexista. Temos, no entanto, consciência de que elas exercem certa influência em sociedade e, em função disso, devemos analisá-las criticamente.

Partindo da perspectiva cultural, Giddens (1993) afirma que a sexualidade humana é mais bem compreendida caso considerarmos o amor e a maneira como os relacionamentos são construídos. Ele destaca que, em especial, uma forma de amor é bastante influente no contexto cultural ocidental: o amor romântico. Esse tem, como uma de suas características principais, a busca de um envolvimento mais permanente com o objeto do amor.

Embora o amor romântico ainda seja influente, as mudanças que estão acontecendo na sociedade proporcionaram o surgimento de novas formas de relacionamentos, como o amor confluente, a sexualidade plástica e o relacionamento puro. $\mathrm{O}$ amor confluente presume que haja uma igualdade na relação, nas trocas afetivas e no envolvimento emocional (ARAÚJO, 2002; GIDDENS, 1993). Araújo (2002) introduz a área erótica no cerne dos relacionamentos conjugais e transforma a realização de prazer sexual recíproco em um elemento importante na manutenção ou na dissolução dos relacionamentos. A sexualidade plástica é livre das necessidades de reprodução, e o relacionamento puro 
privilegia o compromisso, a confiança, a intimidade, a integridade, não se restringindo ao casamento heterossexual. Esse último é diferente da ideia de casamento como uma "condição natural" e "para sempre". o que o torna distinto é a possibilidade de poder ser terminado, mais ou menos à vontade, em qualquer época e por qualquer um dos parceiros.

\section{Metodologia}

A presente pesquisa é de cunho quali/quantitativo, sendo o corpus de investigação composto por 500 anúncios pessoais eletrônicos veiculados no Viva Anúncios (www.vivastreet.com.br), um site gratuito de classificados.

Selecionamos o corpus da pesquisa a partir dos seguintes critérios:

- Anúncios que sejam gratuitos e acessíveis pela internet;

Os processos mentais nas representações de homens e mulheres heterossexuais em anúncios pessoais eletrônicos

- Anúncios escritos em língua portuguesa por falantes nativos;

- Anúncios produzidos no contexto cultural brasileiro;

- Anúncios que contemplem as duas modalidades de interação (homem/mulher e mulher/homem);

- Anúncios publicados no ano de 2014.

Para analisarmos as ocorrências dos processos mentais em nosso corpus de pesquisa, utilizamos a ferramenta WordSmith Tools 6.0, a qual serve, principalmente, para verificar as frequências lexicais. Em nosso trabalho, empregamos as ferramentas "Concord" e "Wordlist", pois desejávamos saber quais os processos mentais mais frequentes e em quais situações eles costumam ser usados.

Os arquivos submetidos ao Wordmisth Tools 6.0 foram nomeados "homem e mulher" e "mulher e homem", "mulher e mulher" e "homem e homem". Cada um deles apresenta 250 anúncios. Cabe destacar que alguns anúncios, em sua forma original, apresentam imagens, porém decidimos não apresentá-las por não termos autorização para veiculá-las.

Organizamos as análises dos processos mentais da seguinte forma:

1) Análise do Corpus 1 [C1] (mulheres e homens)

a) Quando as anunciantes falam de si mesmas;

b) Quando as anunciantes falam de seus parceiros projetados.

2) Análise do Corpus 2 [C2] (homens e mulheres)

a) Quando os anunciantes falam de si mesmos;

b) Quando os anunciantes falam de suas parceiras projetadas. 
Para cada corpus de investigação, foram identificados os processos mentais mais frequentes, bem como analisados seus Fenômenos.

As anunciantes falam de si mesmas

A aplicação do Wordlist no corpus1 (mulher e homem), quando a anunciante fala a respeito de si mesma, mostrou que os processos mentais mais frequentes foram "querer", "procurar", "gostar" "buscar", "adorar" e "amar". A Figura 2 apresenta os dados referentes às quantidades de ocorrências para cada um desses processos.

Vitor Hugo

Chaves Costa

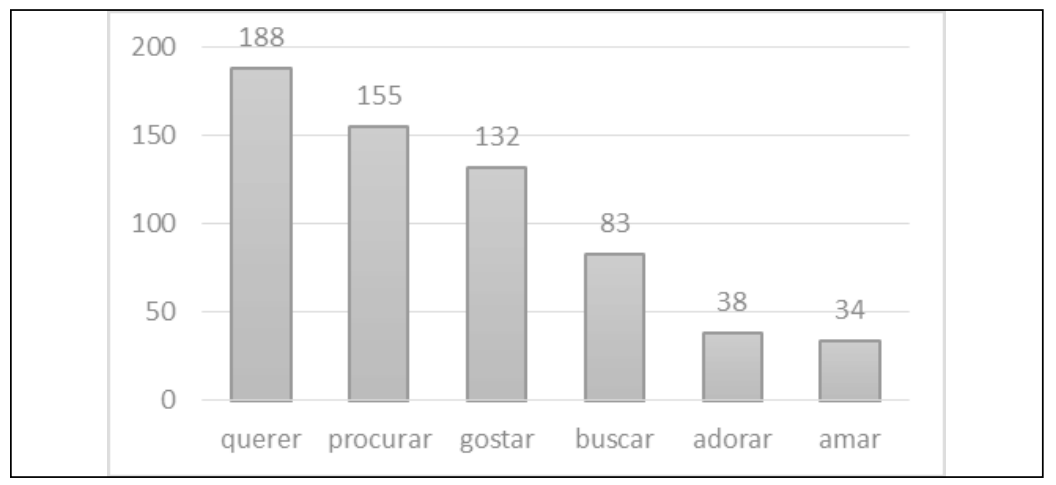

Figura 2: Processos mentais mais frequentes - as anunciantes.

Os seguintes exemplos evidenciam a utilização desses processos mentais mais comumente:

4) Quero arrumar um namorado sério que tenha entre 18 e 32 anos (...) $[\mathrm{C} 1 \# 115]$

5) Procuro homem, inteligente, viúvo ou solteiro, sem filhos, para um relacionamento sério [ $\mathrm{C} 1 \# 71]$.

6) Gosto de ouvir musica (menos funk), sair, ir ao cinema, viajar, conversar, estudar , cozinhar (...) [C1\#45].

7) Busco homem independentes/inteligentes,com a vida resolvida e estabilizada. sincero (fiel) [C1\#35].

8) (..) adoro conversar com amigos e sair beber socialmente [C1\#99].

9) Amo viajar e conhecer sempre novos lugares [C1\#142].

10) Adoro ser tocada na $x x x x$ por homem de 70 anos a mais [C1\#63].

Nos enunciados apresentados, os Experienciadores são sujeitos do sexo feminino, que buscam relacionar-se com sujeitos do sexo masculino. Nos exemplos (4), (5) e (7), podemos observar a utilização dos proces- 
sos mentais desiderativos "querer", "procurar" e "buscar", o primeiro (4) acompanhado de uma oração projetada - "arrumar um namorado sério que tenha entre 18 e 32 anos" - e os outros dois de Fenômenos (5 e 7) que são, respectivamente, "homem, inteligente, viúvo ou solteiro, sem filhos, para um relacionamento sério"e "homem independentes/ inteligentes, com a vida resolvida e estabilizada. sincero (fiel)". Já nos anúncios (6), (8), (9) e (10), notamos a existência de processos mentais emotivos. Nesses casos, os Fenômenos, são: “ouvir musica (menos funk), sair, ir ao cinema, viajar, conversar, estudar , cozinhar", "conversar com amigos e sair beber socialmente", "viajar e conhecer sempre novos lugares" e "ser tocada na xxxx por homem de 70 anos a mais".

No que tange aos Fenômenos e às orações projetadas dos processos mentais mais frequentes, observamos que eles se referem às atividades Os processos mentais nas representações de homens e mulheres heterossexuais em anúncios pessoais eletrônicos de lazer e diversão, quando são utilizados os emotivos, e ao parceiro projetado nas situações de uso dos processos desiderativos. Em decorrência disso, estabelecemos três categorias para classificar os Fenômenos e as projeções dos processos mentais nos anúncios pessoais eletrônicos analisados: recreativo, romântico e sexual. Recreativo, quando se trata de uma atividade de lazer e diversão; romântico, aquele usado nas situações em que o anunciante se refere aos parceiros projetados numa conotação amorosa; sexual quando há conotação erótica ou sexual.

O Quadro 4 mostra os resultados das categorias de Fenômenos para os processos mentais mais empregados.

\begin{tabular}{|c|c|c|c|}
\hline Processo Mental & Recreativo & Romântico & Sexual \\
\hline Querer & $2 \%$ & $95 \%$ & $3 \%$ \\
\hline Procurar & $2 \%$ & $93 \%$ & $5 \%$ \\
\hline Gostar & $84 \%$ & $11 \%$ & $5 \%$ \\
\hline Buscar & $3 \%$ & $90 \%$ & $7 \%$ \\
\hline Adorar & $90 \%$ & $4 \%$ & $6 \%$ \\
\hline Amar & $93 \%$ & $3 \%$ & $4 \%$ \\
\hline
\end{tabular}

Quadro 4: Fenômenos para as anunciantes

Esses resultados referentes aos tipos de processos mentais e às categorias de Fenômenos revelam que as anunciantes se representam como sujeitos que, de fato, buscam se relacionar com alguém, colocando esse desejo em primeiro plano. Podemos afirmar que há elementos culturais (ideologias e representações sociais), influenciando diretamente na seleção dos processos mentais desiderativos para expressar o que elas desejam (MARTIN; ROSE, 2008). Nesse caso, o campo 
Vitor Hugo Chaves Costa (relacionamentos), especialmente na transitividade, está refletindo as mudanças sociais do mundo dos relacionamentos no universo feminino. As mulheres passaram a ser sujeitos que, numa relação amorosa, “querem" e "desejam" (GIDDENS, 1993; ARAÚJO, 2002). o ideal do relacionamento puro, o qual privilegia a confiança, o compromisso, a seriedade, a própria relação e o nível de satisfação para cada um dos parceiros, predomina nessa interação sociodiscursiva (BILAC, 2012). Devemos, no entanto, ressaltar que também há influência do ideal do amor romântico, pois algumas anunciantes buscam alguém que possa completá-las emocionalmente. Verificamos tais aspectos nos seguintes enunciados:

11) Quero uma pessoa com filhos a menos que já sejam adultos pois tenho vontade de conhecer alguém sério pra juntos construirmos uma família e termos mais filhos [C1\#128]. [ROMÂNTICO]

12) Quero arrumar um namorado sério que tenha entre 18 e 32 anos que seja solteiro e pode ter filhos pois adoro crianças [C1\#115]. [ROMÂNTICO]

13) Procuro relacionamento sério (...) [C1\#208]. [ROMÂNTICO]

14) (...) Procuro um companheiro sincero que queira algo serio sem brincadeiras (...) [C1\#182] [ROMÂNTICO]

Como podemos notar, temos a presença do atributo "sério". Esse se refere ao tipo de relacionamento e de parceiro projetado buscado pelas anunciantes, ou seja, há uma evidência da representação do relacionamento puro.

Em segundo plano, as anunciantes se representam como indivíduos que gostam de atividades de lazer e diversão, de modo a expressar suas emoções. Nesta situação, as ideologias e representações do relacionamento puro também estão influenciando na escolha dos processos mentais emotivos (GIDDENS, 1993; MARTIN; ROSE, 2008). Nos exemplos a seguir, percebemos esse tipo de amor:

15) (...) gosto de ir a lugares bacanas [C1\#21].[RECREATIVO]

16) (...),gosto de cozinhar, de boa musica,inclusive gospel! [C1\#24]. [RECREATIVO]

17) (...) adoro conversar com amigos e sair beber socialmente [C1\#99].[RECREATIVO]

18) Amo estar em contato com a natureza [C1\#142]. [RECREATIVO] 
A partir desses resultados apresentados, afirmamos que o acesso ao gênero Anúncio Pessoal Eletrônico pelas anunciantes é mediado pelos discursos, pelas representações sociais e pelas ideologias dos relacionamentos que colocam as mulheres numa situação de alguém que deseja um relacionamento sério, baseado na confiança e na satisfação mútua (MARTIN e ROSE, 2008; BILAC, 2012). Em suma, o uso dos Processos Mentais (Transitividade), em especial, os desiderativos e os emotivos, é fortemente influenciado por tais elementos sociais, culturais e históricos.

\section{As anunciantes falam de seus parceiros projetados.}

A aplicação do Wordlist no corpus1 (mulher e homem), quando as anunciantes falam de seus parceiros projetados, revelou que os processos mentais mais comuns foram "querer", "gostar" e "saber". A Figura 3 apresenta os dados referentes às quantidades de ocorrências para cada um desses processos.

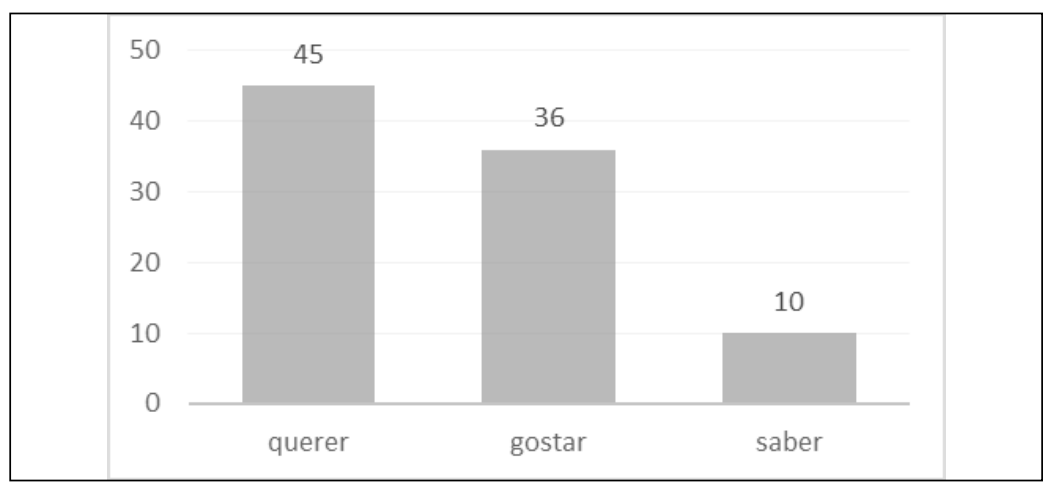

Figura 3: Processos mentais - seus parceiros projetados

Os seguintes enunciados mostram a utilização dos processos mentais mais frequentes:

19) Você que assim quer algo verdadeiro(...) [C1\#233].

20) Companheiro que realmente queira um relacionamento sério [C1\#211].

21) (...) uma pessoa que goste de animais, plantas, crianças em fim que de valor a família [C1\#163].

22) Um amigo que goste de beijar na boca também [C1\#133].

23) Alguém que saiba satisfazer uma mulher de todas as formas [C1\#31].

24) (um homem) que saiba satisfazer e tratar uma mulher como ela merece, sou uma mulher independente, e carinhosa [C1\#36]. 
Vitor Hugo Chaves Costa
Nesses enunciados, os Experienciadores são os parceiros projetados do sexo masculino. Em relação aos Fenômenos para o processo mental desiderativo "querer" em (19) e (20), temos: "algo verdadeiro" e "um relacionamento sério". Já para o processo mental "emotivo" em (21) e (22), o Fenômenos é "de animais, plantas, crianças em fim que de valor a família" e "de beijar na boca também". O processo mental cognitivo "saber" (23 e 24), por sua vez, tem, como complementos, as orações projetadas "satisfazer uma mulher de todas as formas" e "satisfazer e tratar uma mulher como ela merece".

No processo mental desiderativo "querer", foram mais empregados Fenômenos e orações projetadas da categoria "romântico", uma vez que, em geral, as mulheres expressaram o desejo de um relacionamento sério. Para o processo mental emotivo "gostar", novamente prevaleceu a categoria "recreativo", porém a categoria "sexual" foi mais utilizada do que no contexto em que as anunciantes falavam de si mesmas. No processo cognitivo "saber", predominaram os Fenômenos da categoria "sexual". Na seguinte tabela, podemos constatar isso.

\begin{tabular}{|c|c|c|c|}
\hline Processo Mental & Recreativo & Romântico & Sexual \\
\hline Querer & $4 \%$ & $91 \%$ & $5 \%$ \\
\hline Gostar & $82 \%$ & $11 \%$ & $7 \%$ \\
\hline Saber & $4 \%$ & $15 \%$ & $81 \%$ \\
\hline
\end{tabular}

Quadro 5: Fenômenos para parceiros projetados

Esses resultados revelam que, em relação aos parceiros projetados, as anunciantes os representam como sujeitos que "querem" e "desejam" um relacionamento sério, assim como elas. Eles devem gostar de atividades recreativas e alguns aspectos que envolvam a sexualidade. Além disso, esses parceiros devem satisfazê-las sexualmente. Vejamos alguns trechos dos anúncios:

25) (...) queira algo sério pra futuro casamento [C1\#230]. [ROMÂNTICO]

16) Queira ter uma uma família no futuro [C1\#171]. [ROMÂNTICO]

27) um amante que goste de sexo e aventuras sem preconceitos [C1\#46].[ SEXUAL]

28) que goste de passear e de ir ao cinema [C1\#140]. [RECREATIVO]

29) Saiba de fato valorizar e satisfazer uma mulher de verdade [C1\#243]. [SEXUAL]

30) Sabe o que quer e precisa para sua vida [C1\#119]. [ROMÂNTICO] 
Esses exemplos de Fenômenos e orações projetadas revelam que o ideal do amor romântico ainda está influenciando o modo como as anunciantes projetam seus parceiros nos anúncios pessoais eletrônicos, em especial, pelo uso do processo mental desiderativo (GIDDENS, 1993; ARAÚJO, 2002; BILAC, 2012). Isso pode ser comprovado porque muitas mulheres procuram parceiros que queriam casar e construir família, o que é típico do ideal romântico (BOURDIEU, 2005). Por outro lado, elas já reivindicam que seus parceiros gostem de ter relações sexuais e saibam satisfazê-las, o que são características do relacionamento puro (BILAC, 2012).

\section{Os anunciantes falam de si mesmos}

A aplicação do Wordlist no corpus 2 (homem e mulher), quando o anunciante fala de si mesmo, mostrou que os processos mentais mais fre-

Os processos mentais nas representações de homens e mulheres heterossexuais em anúncios pessoais eletrônicos quentes foram "procurar", "querer", "gostar" "buscar", "aguardar" e "adorar". A Figura 4 apresenta os dados referentes às quantidades de ocorrências para cada um desses processos.

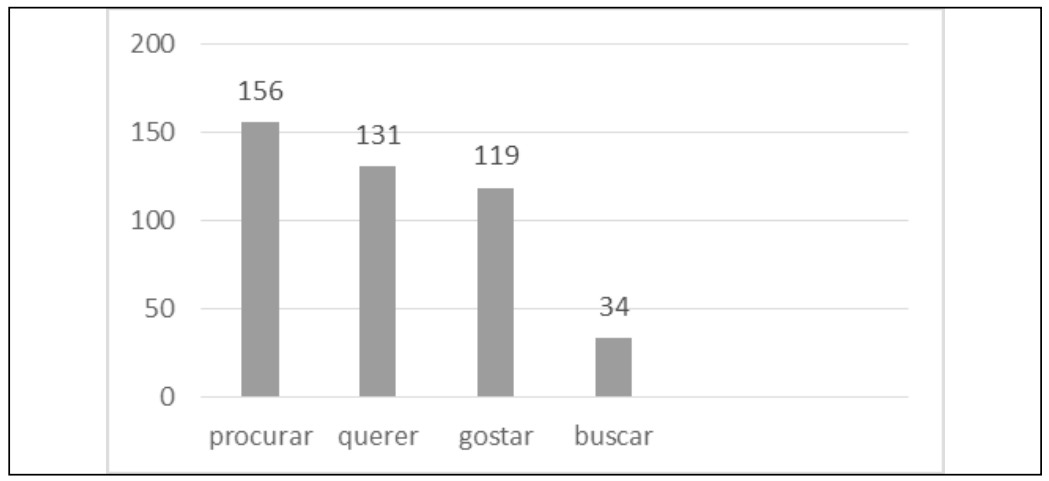

Figura 4: Processos Mentais mais frequentes - os anunciantes

Nos seguintes exemplos, detectamos a utilização desses processos mentais:

31) Procuro uma mulher para algo serio sem brincadeiras [C2\#63].

32) Procuro mulheres jovens para um namoro sério com futuro compromisso [C2\#69].

33) Quero uma mulher que queira ser amada [C2\#34].

34) Quero gordinha com culote, bumbum empinado, pernas grossas [C2\#198].

35) Gosto de músicas internacional romântica, tipo Elton john, Rod Stewart (...) [C2\#50]. 
36) Gosto de mulheres sensiveis e inteligentes [C2\#134].

37) Busco uma mulher que curta homem romântico e simples [C2\#83].

38) Busco uma mulher carinhosa, que me aceite do jeito que sou [C2\#68].

Em (31) e (32), temos o uso do processo mental desiderativo "procurar" com os Fenômenos "uma mulher para algo sério sem brincadeiras" e "mulheres jovens para namoro com futuro compromisso". Nos trechos

Vitor Hugo Chaves Costa (33) e (34), foi empregado o processo mental desiderativo "quero", com os Fenômenos: "uma mulher que queria ser amada" e "gordinha com culote, bumbum empinado, pernas grossas". Já em (35) e (36), foi utilizado o processo mental emotivo "gosto", tendo, como Fenômenos, "de músicas internacional romântica, tipo Elton John, Rod Stewart" e "de mulheres sensíveis e inteligentes". Por fim, em (37) e (38) foi usado o processo mental desiderativo "buscar", com os Fenômenos "uma mulher que curta homem romântico e simples" e "uma mulher carinhosa que me aceite do jeito que sou".

Notamos que os anunciantes estão mais preocupados em expressar seus desejos do que suas emoções, assim como as anunciantes fizeram. Porém, há uma diferença no que concerne aos Fenômenos para os processos mentais mais comumente encontrados nesses anúncios. Nos desiderativos "procurar" e "buscar", predominou a categoria "romântico", já que os anunciantes fizeram menção ao relacionamento. No desiderativo "querer", da mesma maneira, observamos o predomínio da categoria romântico, mas com índice mais significativo da sexual. No emotivo "gostar", por sua vez, temos a presença das categorias romântico e sexual. No Quadro 5, podemos visualizar isso.

\begin{tabular}{|c|c|c|c|}
\hline Processo Mental & Recreativo & Romântico & Sexual \\
\hline Procurar & $3 \%$ & $88 \%$ & $9 \%$ \\
\hline Querer & $7 \%$ & $63 \%$ & $30 \%$ \\
\hline Gostar & $45 \%$ & $27 \%$ & $18 \%$ \\
\hline Buscar & $2 \%$ & $91 \%$ & $7 \%$ \\
\hline
\end{tabular}

Quadro 5: Fenômenos para os anunciantes

Em comparação aos anúncios pessoais eletrônicos de mulheres, percebemos que a categoria sexual foi mais utilizada, especialmente, no processo mental desiderativo "querer". A seguir, apresentamos mais alguns exemplos que mostram as ocorrências de cada um dos tipos de Fenômenos. 
39) Procuro uma Mulher simpática e de bem com a vida $p$ dividir comigo alguns momentos (...) [C2\#02]. [ROMÂNTICO]

40) Procuro uma mulher que tenha algumas afinidades que esteja

Os processos afim de início amizades $\mathrm{p} / \mathrm{um}$ futuro relacionamento sério (...) [C2\#05]. [ROMÂNTICO]

41) Quero namoro com objetivo de casamento de construir uma vida juntos [C\#60]. [ROMÂNTICO]

42) Quero mulheres dispostas a se aventurar no prazer e no extase [C2\#211]. [SEXUAL]

mentais nas

representações

de homens

e mulheres

heterossexuais

em anúncios

43) Gosto de bebidas, cigarros, balada ou noite em claro [C2\#148]; [RECREATIVO]

pessoais

eletrônicos

44) Gosto de sair um pouco,geralmente para algum barzinho bem tranquilo [C2\#195]. [RECREATIVO]

45) Busco uma mulher decidida, fiel e que realmente esteja pronta para algo verdadeiro [C\#189].[ROMÂNTICO]

46) Busco encontra uma mulher de 20 a 30 anos para um relacionamento serio [C2\#122]. [ROMÂNTICO]

Com base nos resultados obtidos, é possível constatarmos que, nos anúncios pessoais dos sujeitos masculinos, especialmente quando eles falam de si mesmos, há influência tanto do ideal de amor romântico quanto do relacionamento puro (BILAC, 2012). Notamos isso, sobretudo, nas situações de uso dos processos desiderativos. Assim, esses influenciam diretamente na seleção de tais processos mentais, os quais apresentam Fenômenos que evocam os ideais românticos e de relacionamento puro (GIDDENS, 1993; HALLIDAY; MATTHIESSEN, MARTIN; ROSE, 2008).

No entanto, devemos considerar que, por fazerem parte do universo masculino, os homens sofrem influências das representações sociais da masculinidade dominante e do heterossexismo, o que também está relacionado ao amor romântico (BOURDIEU, 2005; WELZER-LANG, 2001).

\section{Os anunciantes falam de suas parceiras projetadas.}

A aplicação do Wordlist no corpus 2 (homem e mulher), quando os anunciantes falam de suas parceiras projetadas, revelou que os processos mentais mais frequentes foram "querer" e "gostar". Na Figura 5, a seguir, podemos visualizar as quantidades para os processos mentais utilizados. 
Vitor Hugo

Chaves Costa

136

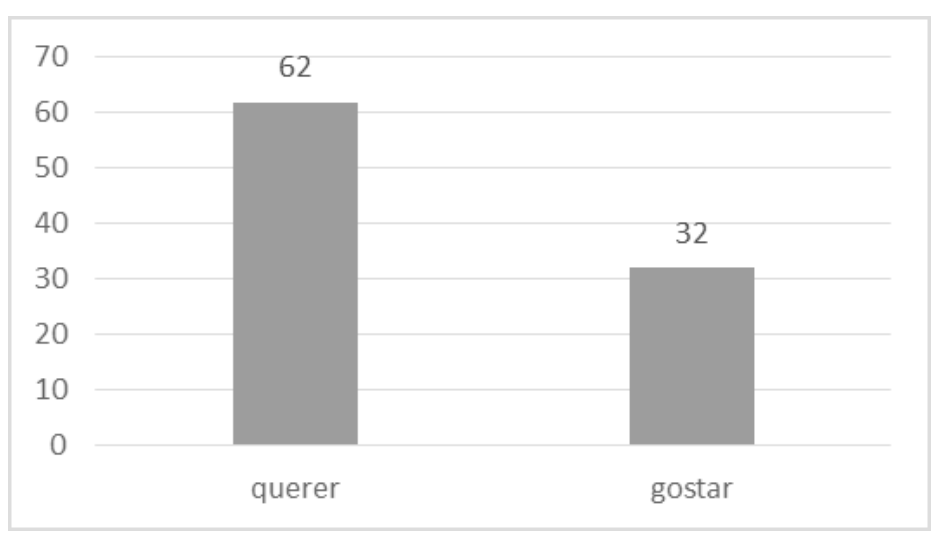

Figura 5: Processos mentais mais frequentes - parceiras projetadas

Os exemplos a seguir mostram o uso dos processos mentais mais comuns nos anúncios em questão.

47) Uma mulher carinhosa que queria descobrir comigo o verdadeiro significado da palavra amor. [C2\#53].

48) Uma mulher verdadeira honesta e carinhosa queira construir um relacionamento a dois [C2\#98].

49) Uma mulher q goste de passear de mão dadas e beijar na boca (...) [C2\#38].

50) Mulher entre 18 e 28, que goste de sair, curtir shoppings, viagens, baladas [C2\#180].

Em (47) e (48), foi empregado o processo mental desiderativo "querer", com as orações projetadas "descobrir comigo o verdadeiro significado da palavra amor" e "construir um relacionamento a dois". O processo mental emotivo, por sua vez, foi usado em (49) e (50), tendo, como complementos, "de passear de mão dadas e beijar na boca" e "de sair, curtir shoppings, viagens, baladas".

Desse modo, concluímos que os homens estão mais interessados nos desejos do que nas emoções de suas parceiras projetadas. Esses desejos estão mais relacionados ao ideal romântico, uma vez que a maioria dos complementos do processo mental "querer" faz alusão ao relacionamento sério. As emoções, por outro lado, rementem à diversão, ao romantismo e à sexualidade. Na tabela a seguir, temos os resultados das categorias complementares de cada um desses processos mentais. 


\begin{tabular}{|c|c|c|c|}
\hline Processo Mental & Recreativo & Romântico & Sexual \\
\hline Querer & $2 \%$ & $90 \%$ & $7 \%$ \\
\hline Gostar & $20 \%$ & $42 \%$ & $38 \%$ \\
\hline
\end{tabular}

Quadro 6: Complementos utilizados para parceiras projetadas

Comparando com os resultados obtidos sobre o que as mulheres esperam dos seus parceiros projetados, notamos que a categoria sexual aparece para o processo "gostar", e a categoria romântico para o processo "querer". Na sequência, há mais alguns exemplos que ilustram o uso desses tipos de Fenômenos e de projeções.

51) (..)uma mulher que queira se envolver sério com de alguém que queria fazer um relacionamento sólido [C2\#230]. [ROMÂNTICO]

52) (...)uma mulher carinhosa romântica e honesta que queira realmente um relacionamento serio [C2\#235]. [ROMÂNTICO]

53) (...) uma mulher honesta e que queira uma Relação séria [C2\#144]. [ROMÂNTICO]

54) (...) uma mulher bonita e que goste muito de sexo e de viver a vida [C2\#194]. [SEXUAL]

55) (...)uma mulher que goste de homem romântico, carinhoso [C2\#188]. [ROMÂNTICO]

56) (...)que goste de mim sem julgar por aparência ou condições de vida. [C2\#213]. [ROMÂNTICO]

Esses resultados mostram que, ao representarem suas parceiras projetadas, os anunciantes ainda estão bastante influenciados pelo ideal do amor romântico, ou seja, imaginam encontrar parceiras que sejam românticas e queiram um relacionamento sério (GIDDENS, BILAC, 2012; ARAÚJO, 2002). Isso também pode ser evidenciado quando eles usam o processo mental "gostar", o qual, diferentemente, não evocava o ideal romântico nos anúncios pessoal das mulheres.

O ideal de amor romântico está muito presente devido à influência da representação social da masculinidade. Tal ideal pressupõe que os homens estariam numa situação mais privilegiada do que as mulheres numa relação amorosa, uma vez que elas seriam românticas e buscariam uma alma-gêmea para torná-las completas e realizadas no amor (BOURDIEU, 2005).
Os processos

mentais nas

representações

de homens

e mulheres

heterossexuais

em anúncios

pessoais

eletrônicos 


\section{Considerações Finais}

No presente artigo, apresentamos uma pesquisa sobre os processos mentais em 500 anúncios pessoais eletrônicos, de homens para mulheres e de mulheres para homens. Cada uma dessas situações de interatividade foi dividida em dois blocos: quando o (a) anunciante fala de si mesmo (a) e quando ele (a) fala de seu/sua parceiro (a) projetado (a). Identificamos os processos mentais mais empregados e classificamos seus Fenômenos ou projeções em três categorias: recreativo, romântico e sexual.

Vitor Hugo Chaves Costa

Nos anúncios de mulheres para homens, ao falarem si mesmas, foram utilizados mais os processos mentais desiderativos (querer, procurar e buscar) e emotivos (gostar, adorar e amar). Os Fenômenos da categoria romântico predominaram nos desiderativos, enquanto que, nos emocionais, foram mais empregados os Fenômenos da categoria recreativo. Isso significa que as mulheres estavam se representando como sujeitos que desejam um relacionamento sério e que gostam de atividades recreativas e de diversão.

Quando as anunciantes se referiam aos seus parceiros projetados, utilizaram mais o processo mental desiderativo (querer), o processo mental emotivo (gostar) e processo mental cognitivo (saber). Em relação aos Fenômenos, predominou a categoria romântico no processo "querer", a categoria recreativo no processo "gostar" e a categoria sexual no processo "saber". Com isso, elas representaram seus parceiros projetados como sujeitos que desejassem um relacionamento sério $\mathrm{e}$ amoroso, que gostassem de se divertir e que soubessem satisfazê-las sexualmente.

Nos anúncios de homens para mulheres, ao falarem de si mesmos, foram empregados mais os processos mentais desiderativos "buscar", "procurar" e "querer" e o processo mental emotivo "gostar". Nos desiderativos, foram utilizados os Fenômenos românticos em grande quantidade. Já no processo mental "gostar", predominou a categoria recreativo, mas o romântico foi também bastante empregado. Destacamos que os Fenômenos da categoria sexual foram muito usados no processo mental "querer". Dessa maneira, concluímos que os homens se representaram como sujeitos que desejavam um relacionamento sério, baseado, principalmente, no romantismo com alguns aspectos da sexualidade (relacionamento puro). Além disso, eles apreciavam atividades de lazer e diversão, sem deixar de lado o romantismo. 
Ao falarem de suas parceiras projetadas, os homens as representaram como mulheres que desejem um relacionamento sério e gostem de se divertir, fazer sexo e que querem ter uma relação romântica. Enfim, elas ainda são representadas com base em ideologias e representações sociais machistas.

Acreditamos que a presente investigação, por tratar de uma questão complexa como as relações de gênero, deve ser aprofundada em futuras pesquisas, utilizando um corpus mais representativo e, se possível, comparando o uso dos processos mentais neste mesmo gênero discursivo em outras línguas. Assim, compreenderemos melhor a dinâmica dos processos mentais nas relações de gênero.

Os processos mentais nas representações de homens e mulheres heterossexuais em anúncios pessoais eletrônicos

\section{Referências}

ARAÚJO, M. F. Amor sexualidade, casamento e sexualidade: velhas e novas configurações. Psicologia: ciência e profissão, v.22. n.2, 2002.

BAKHTIN, M. Estética da criação verbal. São Paulo: Martins Fontes, 2003.

BARBARA, L; MACEDO, C.M. Linguística sistêmico-funcional para análise do discurso: um panorama introdutório. Cadernos de Linguagem e Sociedade, n.10, v. 1, 2009.

BILAC, D.B.N. Transformação da intimidade: homens e mulheres na contemporaneidade na perspectiva da estruturação de Giddens. Revista Travessias, v.6, n.2, 2012, p. 90-105.

BOURDIEU, P. A dominação masculina. 4 ed. Rio de Janeiro: Bertrand Brasil, 2005.

BUTLER, J. Bodies that matter: on the discursive limits of sex. New York: Routledge, 1993.

COUPLAND, J. Dating advertisement: discourses of the commodified self. Discourse and society. v.7. London, Thousand Oaks and New Delhi, 1996, p.187-207. 
EGGINS, S. An introduction to systemic functional linguistics. London: Printer Publishers, 1994.

FUZER, C; CABRAL, S.C. Introdução à linguística sistêmico-funcional em língua portuguesa. Campinas, SP: Mercado das Letras, 2014.

FUZER, C; TICKS, L; CABRAL, S. R. S. Análise sistêmico-funcional como suporte para a leitura de textos: o caso da cerveja Devassa. Revista Brasileira de Linguística Aplicada, v. 12, 2012, p.

Vitor Hugo Chaves Costa 883-909.

GIDDENS, A. A transformação da intimidade: sexualidade, amor e erotismo nas sociedades modernas. São Paulo: UNESP, 1993.

GOUVEIA, C.A.M. Texto e gramática: uma introdução à gramática sistêmico-funcional. Matraga, v.16, n.24, 2009.

HALLIDAY, M. A. K. An introduction to functional grammar. 2nd. ed. London:Arnold, 1994.

HALLIDAY, M. A. K.; HASAN, R. Language, context, and text: aspects of language in a social-semiotic perspective. Oxford: Oxford University Press, 1989.

HALLIDAY, M; MATHIESSEN C. M. I. M. An introduction to functional grammar. Londres: Edward Arnold, 2004.

IKEDA, S. N; VIAN JR, O. A análise do discurso pela perspectiva sistêmico-funcional. In: LEFFA, V. (orgs.). Pesquisa em Linguística Aplicada: temas e métodos. Pelotas: Educat, 2006, p. 37-75.

JESUS, D.M. Educados no sexo neutro: a construção discursiva de sexualidade e de gênero em um texto da revista Veja. Revista Brasileira de Linguística Aplicada. v. 14, n. 3, 2014, p. 613-634.

LOURO, G. L. Um corpo estranho: ensaios sobre a sexualidade e teoria queer. Belo Horizonte: Autentica, 2004. 
MARTIN, J. R. English text: system and structure. Amsterdam: Benjamins, 1992.

MARTIN, J.; WHITE, P. The language of evaluation: appraisal in English. New York: Palgrave, 2005.

Os processos mentais nas representações de homens

MARTIN, J.R; ROSE, D. Genre relations: mapping cultures. London: Equinox, 2008.

e mulheres heterossexuais em anúncios

MOITA-LOPES, L. P. Discursos de identidades. Campinas: Mercado de Letras, 2003.

pessoais eletrônicos

A performance narrativa do jogador Ronaldo como fenômeno sexual em um jornal carioca. Revista da ANPOLL, v. 2, n. 27, 2009, p.128-157.

PRADO, L. L; MOTTA-ROTH, D. Comodificação e homoerotismo. In: HEBERLE, V. M; OSTERMANN, A.C; FIGUEIREDO, D. C. (orgs). Linguagem e gênero: no trabalho, na mídia e em outros contextos. Florianópolis: UFSC, 2006.

PIRES, V.L.; FERRAZ, M. Do machismo ao masculismo: o vínculo das relações de gênero transformou o homem. In: GHILARDI-LUCERNA, M; OLIVEIRA (orgs). Representações do masculino: mídia, literatura e sociedade. Campinas, SP: Alínea, 2008.

SILVA, S. G. A crise da masculinidade: uma crítica à identidade de gênero e à literatura masculinista. Psicologia: ciência e reflexão, v.26, n.1, 2006.

SOARES, J.P. Representações semântico-discursivas de atitude avaliativa de uma professora de inglês da rede pública de ensino acerca dos usos do livro didático em sala de aula. Dissertação de Mestrado em Letras. Ouro Preto: Programa de Pós-Graduação em Letras da Universidade Federal de Outro Preto, 2013.

THOMPSON, G. Introducing functional grammar. 3. ed. Londres: Arnold, 2014. 
VIAN JR, O; LIMA-LOPES, R.E. A perspectiva teleológica de Martin para a análise de gêneros textuais. MEURER, J.L; BONINI, A; MOTTA-ROTH, D. (Orgs). Gêneros: teorias, métodos, debates. São Paulo: Parábola Editorial, 2005.

VIAN JR, O. Estruturas potenciais de gêneros na análise textual e no ensino de línguas. Linguagem em (Dis)curso, v. 9, p. 387-410, 2009.

WELZER-LANG, D. A construção do masculino: a dominação das

Vitor Hugo Chaves Costa

\section{Site consultado}

www.vivastreet.com.br 